\title{
SAÚDE FINANCEIRA DOS COLABORADORES: GESTÃO DA QUALIDADE DE VIDA NO TRABALHO
}

\author{
HARDER, Eliana Martuccello'; BRAGA, Hilda Maria Cordeiro Barroso².
}

\begin{abstract}
RESUMO
O estudo se fundamenta na análise da crise econômica brasileira, iniciada em 2014, que expôs grande parcela da população a sacrifícios para manter o padrão de vida minimamente digno e gerou aumento do endividamento pessoal. Neste cenário surge o chamado estresse financeiro que, quando manifestado por funcionários de empresas, compromete o seu desempenho profissional. A pesquisa avalia, por meio de levantamento de campo, a presença ou não de estresse financeiro comprometendo o desempenho profissional dos colaboradores das empresas, principalmente da região Bragantina, sob a ótica dos gestores de RH, e identifica como as empresas lidam com estas questões e se adotam medidas preventivas para minimizá-las. Os resultados mostram que o principal problema financeiro apontado é o aumento com dívidas dos funcionários $(56,6 \%)$ e o maior impacto disso é a queda da produtividade $(71,7 \%)$. Porém, somente $26,1 \%$ das empresas promovem ações de educação financeira para os funcionários, embora entendam que ações preventivas ajudariam a melhorar a qualidade de vida dos funcionários $(63 \%)$, mas sem reflexos no aumento da produtividade (41\%). Estes resultados indicam a importância das finanças pessoais para as empresas e os colaboradores, garantindo maior qualidade de vida para os funcionários e, indiretamente, podendo melhorar a produtividade para as empresas. No entanto, os investimentos em educação financeira não são expressivos, já que a percepção é de não haver retorno financeiro para a empresa.
\end{abstract}

Palavras-chave: Finanças. Dívidas. Qualidade de Vida no Trabalho (QVT). Estresse Financeiro.

\begin{abstract}
The study is based on the analysis of the Brazilian economic crisis, which began in 2014 and exposed a large part of the population to sacrifices to maintain a minimally dignified standard of living. This crisis generated an increase in personal indebtedness. In this scenario emerges the socalled financial stress that, when manifested by employees of companies, compromises their professional performance. These research through field surveys evaluates the presence or absence of financial stress that compromised the professional performance of company employees, especially in the Bragantina Region, from the perspective of Human Resources (HR) managers. Further it identifies how companies deal with these issues and take preventive measures to minimize them. The results show that the main financial problem is the increase with employee debts $(56.6 \%)$ and the biggest impact is the fall in productivity (71.7\%). However, only $26.1 \%$ of the companies promoted financial education actions for employees, although they understood that preventive actions would help improve the quality of life of employees (63\%), but without any impact on productivity growth $(41 \%)$. These results indicate the importance of personal finance for companies and employees, ensuring a higher quality of life for employees and, indirectly, improving productivity for companies. Nevertheless, investments in financial education are not expressive, since the perception is that there is no financial return for the company.
\end{abstract}

Keywords: Finance. Debt. Life Quality at Work (LQW). Financial Stress.

\footnotetext{
1 Acadêmica do Programa de Pós-graduação lato sensu "MBA em Gestão Financeira e Controladoria" do Centro Universitário UNIFAAT. Mestre em Educação, especialista em Sistemas de Informação e graduada em Economia. Docente do Centro Universitário UNIFAAT.

2 Doutora em Educação, mestre em Administração de Empresas, graduada em Letras e Pedagogia. Professora de graduação e pós-graduação, pesquisadora e coordenadora da área de pós-graduação e extensão do Centro Universitário UNIFAAT.
} 


\section{Introdução}

A saúde financeira de um povo depende de inúmeros fatores, tais como o desempenho econômico do país, o nível de conhecimento e educação financeira das pessoas, o comportamento e as crenças da população em relação ao dinheiro, dentre outros. As crises econômicas desestruturam a base material na qual estão assentadas famílias e empresas gerando muita insegurança e medo. Aliado a isto nos últimos anos houve um aumento da complexidade dos produtos financeiros oferecidos pelo mercado. Diversas opções de investimento, crédito, financiamento estão disponíveis no mercado financeiro.

Por isso, programas visando a ampliar a educação financeira das pessoas ganham relevância a partir da crise imobiliária iniciada nos Estados Unidos da América, no final de 2007. A OECD, em português, OCDE (Organização de Cooperação e de Desenvolvimento Econômico) impulsionou esse movimento que recebeu adesão de outros órgãos e países, dentre os quais o Brasil (OECD, 2004).

Diante de uma realidade econômica cheia de incertezas, mudanças e crises, aumentaram os estudos e pesquisas sobre o impacto que estas situações geram nas pessoas. Pesquisas realizadas em diferentes países como Estados Unidos da América, Inglaterra e Brasil apontam que problemas de ordem financeira causam um grande estresse nas pessoas. A falta de dinheiro para o sustento da família, o atraso no pagamento das contas, a inadimplência, o endividamento, a insegurança com o futuro e a aposentadoria geram o chamado estresse financeiro, contribuindo para o surgimento de doenças, problemas e desequilíbrios físicos e emocionais.

A grave crise econômica iniciada em 2014, no Brasil, expôs uma grande parcela da população a grandes sacrifícios para manter um padrão de vida minimamente digno e gerou grande estresse financeiro.

Estudos e pesquisas mostram que o estresse financeiro apresentado por funcionários de empresas compromete o seu desempenho profissional, provocando aumento de faltas, queda da produtividade e aumento de acidentes de trabalho (SOUZA, 2013).

Para tanto, o problema em pauta, desta pesquisa, como as empresas lidam com estas questões e, ainda, se adotam medidas preventivas para minimizá-las?

Diante disto, o trabalho tem por objetivo identificar a presença ou não de elementos de saúde financeira dos funcionários das empresas da região Bragantina sob a ótica dos profissionais de RH, por meio de pesquisa de campo. 


\section{Referencial Teórico}

\subsection{Educação Financeira}

Em diversos países estão sendo criadas iniciativas para se levar educação financeira para as escolas, incentivados pela OECD, que preconiza a importância deste tema para auxiliar os consumidores a orçar e gerir a sua renda, a poupar e investir, e a evitar que se tornem vítimas de fraudes (OECD, 2004).

A educação financeira está mais desenvolvida nos Estados Unidos, Reino Unido, Canadá, Austrália e Nova Zelândia, e em alguns países da América Latina e da Europa Central e Oriental (HOLZMANN; MIRALLES, 2005 apud SAVOIA; SAITO; SANTANA, 2007). Nos Estados Unidos há uma grande quantidade de instituições envolvidas no processo de educação financeira. Mais da metade dos estados americanos tornaram a educação financeira obrigatória nas escolas secundárias (BERNHEIN; GARRETT; MAKI, 1997 apud SAVOIA; SAITO; SANTANA, 2007).

Um estudo sobre os efeitos da educação financeira em empresas é realizado nos Estados Unidos pela fundação Personal Finance Employee Education Foundation (PFEEF), que desenvolveu um modelo para mensurar o retorno do investimento (ROI) em educação financeira pelas empresas. Segundo estes estudos, o ROI de um programa de educação financeira em uma empresa pode chegar a três dólares para cada dólar investido (GARMAN, 2007).

No Brasil a educação financeira começou a ganhar importância com a criação, pelo Governo Federal, da ENEF (Estratégia Nacional de Educação Financeira) em 2010, com o objetivo de fornecer e apoiar ações que ajudam as pessoas a tomar decisões financeiras mais autônomas e conscientes (BRASIL, 2010).

Hoje existem inúmeras iniciativas públicas e privadas que oferecem educação financeira no Brasil, segundo dados da ENEF (2018). No entanto, essas ações foram insuficientes para evitar o elevado grau de endividamento vivido por grande parte das famílias brasileiras nos últimos anos. Por isso, a necessidade de se ampliar o debate acerca deste tema, bem como o envolvimento de pessoas, empresas e Governo para a melhoria do ambiente econômico do país. 


\subsection{Ciclos econômicos e breve panorama da economia brasileira nos últimos 10 anos}

O desempenho da economia impacta diretamente na vida das famílias e nas suas finanças pessoais transparecendo nos seus hábitos de consumo, na propensão a poupar e investir e na predisposição para a tomada de crédito e endividamento.

Durante os últimos 10 anos, as famílias brasileiras vivenciaram momentos de uma relativa prosperidade econômica seguida de uma profunda e grave recessão.

De fato, a literatura econômica aponta para a existência de ciclos econômicos nos países capitalistas desde o século XIX que tradicionalmente são divididos em duas fases: expansão e contração (MORAIS, 2013).

Um ciclo econômico consiste de expansões ocorrendo mais ou menos ao mesmo tempo em muitas atividades econômicas e por recessões, contrações e reavivamentos similares que se fundem à fase de expansão do próximo ciclo podendo variar mais de 1 ano até 10 ou 12 anos (BURN; MITCHELL, 1946 apud DIEBOLD; RUDEBUSCH, 1996).

A exemplo dos Estados Unidos da América, que possui o Comitê de Datação de Ciclo de Negócios do National Bureau of Economic Research (NBER), a Fundação Getúlio Vargas (FGV) criou o Comitê de Datação de Ciclos Econômicos (CODACE) para estabelecer uma cronologia de referência para os ciclos econômicos brasileiros e servir de base para estudiosos, empresas e Governo.

O CODACE apontou duas recessões econômicas nos últimos 10 anos, sendo a primeira ocorrida entre o $4^{\circ}$ trimestre de 2008 até o $1^{\circ}$ trimestre de 2009 , com duração de 6 meses, e a segunda entre o segundo trimestre de 2014 e o quarto trimestre de 2016 (FGV-RJ, 2009).

De fato, a partir de 2014 a economia brasileira começa a perder o seu dinamismo, mergulhando em 2015 e 2016 em uma profunda recessão. O estudo da CODACE/IBRE/FGV identificou a ocorrência de um pico no ciclo de negócios brasileiro no primeiro trimestre de 2014 que representa o fim de uma expansão econômica de 20 trimestres (entre o segundo trimestre de 2009 e o primeiro de 2014) e sinaliza a entrada do país em uma recessão a partir do segundo trimestre de 2014 (CODACE, 2015).

Em 2015 o PIB sofreu uma retração de 3,8\%, posteriormente revisada pelo IBGE para $3,5 \%$ (IBGE, 2017).

O Fundo Monetário Internacional (FMI), em seu relatório "Perspectiva Econômica Regional: Hemisfério Ocidental”, divulgado em 29 de abril de 2015, afirma que o Brasil vive 
o mais severo ciclo de desaceleração econômica em mais de duas décadas (BARBOSA, 2015).

Consequentemente, houve um aumento expressivo da taxa de desemprego. O mercado de trabalho brasileiro encerrou o segundo trimestre de 2017 com 26,3 milhões de trabalhadores desocupados e subocupados, segundo a Pesquisa Nacional por Amostra de Domicílios (PNAD) divulgada pelo Instituto Nacional de Geografia e Estatística (IBGE, 2018).

Em reportagem para o G1 Economia, Silveira (2017) aponta que a

[...] taxa composta de subutilização da força de trabalho agrega os trabalhadores desempregados, aqueles que estão subocupados (por poucas horas trabalhadas) e os que fazem parte da força de trabalho potencial, mas não estão procurando emprego por motivos diversos.

Por conta do elevado índice de pessoas desempregadas e subocupadas a renda das famílias diminuiu em 2017. A população perdeu $0,56 \%$ no rendimento total mensal real na comparação com o ano anterior. Considerando somente o rendimento proveniente do trabalho a queda é de 1,36\%, segundo o levantamento da Pesquisa Nacional por Amostra de Domicílios Contínua do Instituto Brasileiro de Geografia e Estatísticas (IBGE, 2018).

A consequência do aumento expressivo do desemprego foi a diminuição da renda e do consumo, criando um círculo vicioso na economia com a queda do nível da produção e das vendas gerando mais desemprego (DANA, 2016).

\subsection{Impacto da economia nas finanças pessoais}

O impacto desta longa e intensa recessão foi muito significativo na vida das famílias.

Diversas pesquisas apontam para o elevado percentual de pessoas que comprometem parte dos seus rendimentos para o pagamento de dívidas ou encontram-se inadimplentes.

Em abril de 2018 foi apurado pela Pesquisa Nacional de Endividamento e Inadimplência do Consumidor (Peic) da Confederação Nacional do Comércio de Bens, Serviços e Turismo que $25 \%$ das famílias estavam com dívidas ou contas em atraso e 10,3\% não têm condições de pagar suas contas ou dívidas em atraso e que, portanto, permaneceriam inadimplentes (CNC, 2018).

A pesquisa feita pelo Serviço de Proteção ao Crédito (SPC Brasil) em parceria com a Confederação Nacional de Dirigentes Lojistas (CNDL) afirma que como reflexo da recuperação lenta do emprego e da renda, o total de brasileiros com alguma conta em atraso 
chegou a 62,2 milhões em abril de 2018 ou 41\% da população adulta do País (LAGUNA, 2018).

\subsection{Impactos do estresse financeiro}

O estresse é apontado por médicos e psicólogos como um desencadeador de inúmeras doenças, problemas e desequilíbrios físicos e emocionais. Dentre os vários fatores desencadeadores do estresse o foco desta pesquisa está no fator financeiro.

Loiola (2014) afirma que o estresse financeiro pode ser descrito como uma preocupação excessiva com os problemas financeiros pessoais diante da incapacidade de equacioná-los.

\footnotetext{
Um estudo feito em 2016 nos Estados Unidos pela empresa de bem-estar financeiro Payoff (2016) teve um resultado ainda mais alarmante. Os pesquisadores descobriram que $23 \%$ da amostra apresentaram sintomas de comumente associados a Transtorno de Estresse Pós-Traumático - TEPT com relação às suas finanças. Entre Millenials, este percentual foi de $36 \%$. Essas pessoas apresentaram um quadro de estresse financeiro agudo (Acute Financial Stress), com comportamentos irracionais, evasivos e de negação, deixando-as menos capazes para planejar e gerenciar suas vidas financeiras (SOUZA, 2017, p.16).
}

O departamento de comércio e indústria inglês elaborou relatórios sobre o super endividamento naquele país e concluiu que isto pode ser muito prejudicial para as pessoas, contribuindo para a pobreza, a exclusão social e financeira, sendo associado a doenças físicas e mentais (LOIOLA, 2014).

A American Psychological Association (2017) publica anualmente uma pesquisa sobre as causas e consequências do estresse nos Estados Unidos da América, que afirma que o dinheiro (gestão das finanças, endividamento, investimentos, previdência etc.) foi a principal fonte de estresse dos americanos nos últimos anos.

Segundo Massaro (2017) faltam pesquisas no Brasil sobre esse tema. Mas que os números apresentados pela pesquisa americana refletem resultados similares em outros lugares do mundo, inclusive no Brasil.

Souza (2017) acredita que as causas, características e efeitos do estresse financeiro devam ser os mesmos para brasileiros, especialmente diante de instabilidades políticas, econômicas e legais, que geram apreensões quanto à qualidade do futuro.

Os estudos do professor E. Thomas Garman, da Virginia Tech University, nos Estados Unidos da América, mostram que os trabalhadores com problemas financeiros apresentam maiores índices de faltas e atrasos. Além de utilizarem o seu tempo e os recursos da empresa 
na busca de soluções para seus problemas. Também apontam para o aumento de furtos nas empresas e uma maior demanda por adiantamentos e empréstimos (EID JUNIOR, 2009).

No Brasil, o professor Eid Jr. realizou em 2008 estudos com funcionários da Fundação Getúlio Vargas de São Paulo sobre o seu grau de estresse financeiro concluindo que quanto maior o estresse financeiro, maior o número de faltas (EID JUNIOR, 2009).

Uma pesquisa realizada com 673 funcionários de 10 grupos empresariais brasileiros de diferentes setores de atuação concluiu que há uma relação de causalidade estatisticamente significativa entre o estresse financeiro individual e o comportamento do profissional brasileiro no ambiente de trabalho. Quanto maior o grau de estresse financeiro, maior é a probabilidade de faltas, especialmente aquelas de natureza injustificada. Esses resultados indicam que o efeito do estresse financeiro no comportamento de profissionais brasileiros é similar ao efeito já documentado no exterior, notadamente nos Estados Unidos da América, por inúmeros estudos, dentre os quais: Society for Human Resource Management (2014), Price Water House Coopers (2017), Lockton Retirement Services (2016), Joo e Garman (1998) e Hendrix, Steel e Shultz (1987) (SOUZA, 2017).

A Pesquisa de Bem-estar Financeiro do Empregado (Employee Financial Wellness Survey 2012) da Price Water House Coopers revela que, em média, nos Estados Unidos, 97\% dos funcionários utilizam horas de trabalho para cuidar das questões financeiras pessoais. Sendo que $22 \%$ dos trabalhadores direcionam pelo menos 20 horas por mês correndo atrás das suas finanças dentro do ambiente da empresa (MARTINS, 2014). Segundo o especialista em finanças pessoais André Massaro (2017), o problema financeiro gera estresse e faz com que o empregado se concentre menos no trabalho. A falta de controle orçamentário dentro de casa tira tanto a atenção dos trabalhadores que chega até a gerar acidentes na companhia.

$\mathrm{O}$ estresse financeiro de um funcionário também pode resultar em uma série de custos para a empresa em função de faltas, atrasos constantes, problemas de relacionamento com colegas de trabalho, sabotagem de trabalho dos colegas, estresse no trabalho e diminuição de produtividade (GARMAN et al. (1996) apud ELISSON, 2012).

\section{Método}

\subsection{Tipo e Método da Pesquisa}

Foi realizada uma pesquisa descritiva, com levantamento de campo por meio de questionário de múltipla escolha, sustentada pela revisão da literatura por meio da coleta de 
dados em fontes secundárias, teses, dissertações, artigos, sites especializados etc. Antecedendo à preparação da pesquisa de campo, procedeu-se a revisão da literatura sobre os conceitos de educação financeira, estresse financeiro, qualidade de vida no trabalho e produtividade, cujos principais autores abordados são Eid Junior (2018), Laguna (2018), Loiola (2014), Souza $(2013,2017)$.

\subsection{Sujeitos e a Amostra}

A amostra da pesquisa é composta por 45 profissionais de RH que atuam em empresas do Estado de São Paulo, principalmente na região Bragantina (Atibaia, Bragança Paulista, Itatiba, Jarinu, Nazaré Paulista e Piracaia), na sua maioria do setor industrial com médio porte. No entanto, houve uma boa participação de empresas da cidade de São Paulo e região do ABC Paulista e também do setor de serviços. Portanto, a amostra abrangeu empresas do interior paulista e capital de todos os setores e portes econômicos.

\subsection{Instrumentos}

Para levantamento dos dados necessários à realização desta pesquisa, elaborou-se um questionário com quatorze (14) perguntas abertas e fechadas de múltipla escolha.

Este questionário foi dividido em duas partes distintas: na primeira parte as questões foram elaboradas para possibilitar a caracterização do respondente e da empresa, identificando-se a função do respondente e a localização, porte e ramo de atividade da empresa no intuito de traçar o perfil das empresas participantes.

$\mathrm{Na}$ segunda parte as questões referem-se à saúde financeira dos funcionários da empresa, os possíveis problemas e interferências causados na empresa e as medidas adotadas para minimizá-los.

\subsection{Procedimentos}

Os dados coletados na primeira parte deste estudo seguiram as etapas sugeridas pelos autores Lakatos e Marconi (2001), assim as informações neste estudo seguem os seguintes procedimentos: na parte do referencial teórico o tratamento é qualitativo, isto porque as informações contidas neste tópico são a partir de interpretações e leitura de obras que retratam os temas ali discutidos. 
$\mathrm{Na}$ pesquisa de campo o tratamento é quantitativo, uma vez que neste item são apresentadas as tabulações em forma de gráficos das respostas fornecidas pelos profissionais que responderam aos questionários, aqui os dados se encontram quantificados e qualitativos, pois haverá uma análise diante dos resultados.

A coleta de dados foi efetuada mediante o envio de formulário eletrônico aos profissionais de RH das empresas para participar da pesquisa, explicando o teor e a finalidade da pesquisa. A adesão desses profissionais à pesquisa era opcional e sem a necessidade de se identificar. O formulário eletrônico utilizado foi o Google Docs, cujo questionário ficou disponível entre os dias 11 de junho a 13 de julho de 2018.

\section{Resultados}

O formulário da pesquisa foi respondido majoritariamente por profissionais de RH de empresas da região Bragantina, especialmente: Atibaia, Bragança Paulista, Itatiba, Jarinu, Nazaré Paulista e Piracaia, representando 64\% do total de respostas, e da região da Grande São Paulo com $20 \%$ das respostas, conforme demonstra a tabela 1:

Tabela 1: Localização geográfica das empresas

\begin{tabular}{|l|c|c|}
\hline Municípios & $\begin{array}{l}\text { Quant. } \\
\text { Empresas }\end{array}$ & $\%$ \\
\hline Região Bragantina & 29 & $64 \%$ \\
\hline $\begin{array}{l}\text { São Paulo e ABC } \\
\text { Paulista }\end{array}$ & 9 & $20 \%$ \\
\hline $\begin{array}{l}\text { Extrema e Sul de } \\
\text { Minas Gerais }\end{array}$ & 2 & $4 \%$ \\
\hline $\begin{array}{l}\text { Outras cidades do } \\
\text { Estado de São Paulo }\end{array}$ & 5 & $11 \%$ \\
\hline Total & $\mathbf{4 5}$ & $\mathbf{1 0 0 \%}$ \\
\hline \multicolumn{2}{|c|}{ Fonte: Elaborado pela autora. } \\
\hline
\end{tabular}

As empresas pesquisadas são na sua maioria do setor industrial $(41,3 \%)$ e possuem médio porte $(41,3 \%)$.

As empresas têm na média 312 funcionários, sendo que a menor empresa tem somente 1 colaborador e a maior empresa tem 3.800 colaboradores.

Participaram da pesquisa de forma expressiva os seguintes profissionais de RH: analistas $(32,6 \%)$, supervisores/coordenadores $(26,1 \%)$ e gerentes $(23,9 \%)$.

Os principais problemas financeiros pessoais relatados pelos funcionários aos profissionais de RH são o aumento das suas dívidas $(56,6 \%)$ com cartão de crédito, cheque 
especial, empréstimos e financiamentos, seguidos pelo aumento das suas despesas com problemas de saúde $(13 \%)$.

Segundo os profissionais de $\mathrm{RH}$, os principais impactos no desempenho profissional causados por problemas financeiros pessoais dos funcionários são a queda da produtividade (71,7\%), o aumento do absenteísmo (13\%) e o aumento de doenças laborais (10,9\%), de acordo com o gráfico 1 .

Gráfico 1: Percepção sobre o impacto que os problemas financeiros pessoais causam no desempenho dos funcionários.

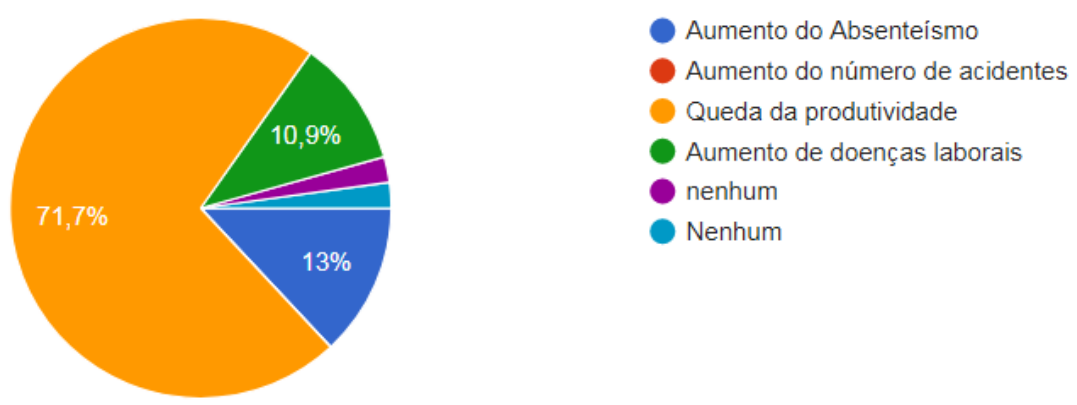

Fonte: Elaborado pela autora.

A grande maioria das empresas relatou que não possui nenhum sistema de métrica (acompanhamento de indicadores) sobre os problemas financeiros dos funcionários. Somente três empresas utilizam, como indicador de saúde financeira, informações sobre os empréstimos consignados dos funcionários.

Somente $26,1 \%$ das empresas promovem ações de educação financeira para os funcionários, como cursos, workshops e orientação financeira com especialistas.

No entanto, quando comparamos os dados das empresas de São Paulo/ABC com a Região Bragantina, observamos que $44 \%$ das empresas de São Paulo/ABC investem em educação financeira, contra somente $17 \%$ das empresas da Região Bragantina.

Todas as empresas de São Paulo/ABC que responderam investir em educação financeira para os seus colaboradores são do setor de serviços e a maioria tem pequeno porte. Já as empresas da Região Bragantina são na sua maioria do setor industrial e têm médio porte $(60 \%)$.

A maioria dos profissionais de $\mathrm{RH}(63 \%)$ respondeu que o fator mais relevante para a empresa, caso promovessem educação financeira, seria um aumento da qualidade de vida dos funcionários e que este deveria ser o objetivo das empresas ao adotar essas ações $(56,5 \%)$. Gráfico 2. 


\section{Gráfico 2: Fatores relevantes para as empresas ao investir em educação financeira.}

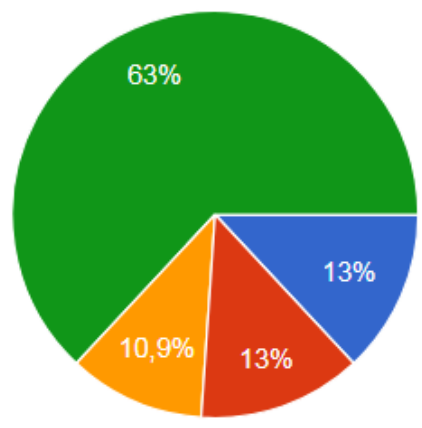

Aumento da produtividade

Valorização pelos funcionários dos benefícios oferecidos pela empresa

Fortalecimento da marca/empresa através de ações de promovem a sua responsabilidade social

Aumento da qualidade de vida do funcionário

Fonte: Elaborado pela autora.

Além do aumento da qualidade de vida dos funcionários, um plano de educação financeira com acompanhamento de resultados melhoraria o planejamento e controle financeiro $(47,8 \%)$ e o bem-estar e desempenho profissional $(32,6 \%)$.

Quarenta e um por cento (41\%) dos profissionais de $\mathrm{RH}$ responderam que o retorno de um possível investimento na promoção de educação financeira ocorreria somente no sentido de um aumento da qualidade de vida dos funcionários. Enquanto outros $41 \%$ acreditam que o retorno financeiro deveria ser mais que o dobro do valor investido $(25,6 \%)$ ou haveria empate entre o investimento e o retorno financeiro $(15,4 \%)$.

\section{Análise e interpretação dos resultados}

Os resultados da pesquisa mostram que os principais problemas financeiros apontados pelos profissionais de RH das empresas pesquisadas são o aumento das dívidas realizadas pelos funcionários $(56,6 \%)$ com cartão de crédito, cheque especial, empréstimos e financiamentos, seguidos pelo aumento das suas despesas com problemas de saúde (13\%).

Estes resultados refletem a situação econômica vivida pelo país nos últimos anos, que passou por uma forte recessão em 2015 e 2016 (CODACE, 2015) ocasionando um aumento expressivo da taxa de desemprego e da renda (IBGE, 2018). E vai ao encontro dos dados apurados pela pesquisa realizada pelo Serviço de Proteção ao Crédito (SPC Brasil) em parceria com a Confederação Nacional de Dirigentes Lojistas (CNDL), que afirma que como reflexo da recuperação lenta do emprego e da renda, o total de brasileiros com alguma conta em atraso chegou a 62,2 milhões em abril de 2018, ou seja, 41\% da população adulta do país (LAGUNA, 2018). 
Segundo os profissionais de $\mathrm{RH}$ das empresas pesquisadas os principais impactos desses problemas financeiros dos funcionários são a queda da produtividade $(71,7 \%)$, o aumento do absenteísmo (13\%) e o aumento de doenças laborais (10,9\%).

Esses resultados corroboram as informações descritas em estudos semelhantes como de Eid Junior (2018), Laguna (2018), Loiola (2014) e Souza (2013, 2017).

No entanto, a grande maioria das empresas pesquisadas relatou que não faz nenhum acompanhamento de indicadores sobre os problemas financeiros dos funcionários e somente 26,1\% das empresas promovem ações de educação financeira para os funcionários, como cursos, workshops e orientação financeira com especialistas. Mas elas entendem que ações preventivas ajudariam a melhorar a qualidade de vida dos funcionários (63\%) aumentando o planejamento e controle financeiro (47,8\%), o bem-estar e desempenho profissional $(32,6 \%)$.

O principal objetivo das empresas caso investissem em educação financeira seria o aumento da qualidade de vida do trabalhador $(56,5 \%)$. O aumento da produtividade, principal problema apontado, é citado por somente $15,2 \%$ das empresas. O que denota a percepção de que o investimento em educação financeira não reflete em aumento de produtividade. O que é evidenciado por $41 \%$ das empresas que responderam que o retorno de um possível investimento na promoção de educação financeira ocorreria somente no sentido de um aumento da qualidade de vida dos funcionários, contra $(25,6 \%)$ que acreditam que o retorno financeiro deveria ser mais que o dobro do valor investido.

A percepção de que o investimento em educação financeira não traz retorno para a empresa não reflete os estudos da fundação americana Personal Finance Employee Education Foundation. O retorno do investimento (ROI) de um programa de educação financeira em uma empresa americana pode chegar a três dólares para cada dólar investido (PFEEF).

\section{Considerações finais}

O trabalho realizado avaliou, por meio de pesquisa de campo, a presença de estresse financeiro comprometendo o desempenho profissional dos colaboradores das empresas, principalmente da região Bragantina.

Os profissionais de RH relataram que têm ciência dos problemas financeiros dos seus colaboradores, principalmente em relação ao aumento das dívidas (cartão de crédito, cheque especial, empréstimos e financiamentos) e dos gastos com problemas de saúde. Assim como dos impactos no desempenho profissional dos funcionários, tais como a queda da produtividade, o aumento do absenteísmo e o aumento de doenças laborais. 
No entanto, a maioria das empresas não faz nenhum acompanhamento de indicadores sobre os problemas financeiros dos funcionários e poucas empresas promovem ações de educação financeira. Somente $17 \%$ das empresas da Região Bragantina investem em educação financeira contra $44 \%$ das empresas de São Paulo/ABC.

Paradoxalmente, a queda da produtividade não é vista pelos profissionais de RH como o fator mais relevante para as empresas, caso investissem em educação financeira para os funcionários, como sugere a literatura sobre este assunto.

Por outro lado, todas as empresas afirmam que a promoção de ações preventivas, no sentido de capacitar os colaboradores para lidar de forma mais saudável com as suas finanças, ajudaria a melhorar a qualidade de vida dos funcionários. Desta forma, a educação financeira favoreceria o planejamento e controle financeiro, além de proporcionar aumento do bem-estar e desempenho profissional.

Portanto, os resultados desta pesquisa indicam a importância das finanças pessoais para as empresas e para os colaboradores, garantindo maior qualidade de vida para os funcionários, embora os investimentos em educação financeira não sejam expressivos, já que a percepção das empresas é de baixo retorno do investimento.

Neste sentido, seria de grande relevância ampliar os estudos sobre os impactos e retorno financeiro de programas de educação financeira nas empresas, assim como a criação de indicadores de saúde financeira pessoal.

\section{Referências}

AMERICAN PSYCHOLOGICAL ASSOCIATION. Stress in America: coping with change, part 1. Washington, DC: American Psychological Association, 2017. Disponível em: http://www.apa.org/news/press/releases/stress/2016/coping-with-change.PDF. Acesso em: 16 maio 2018.

ANDRADE, E. Tópicos Avançados em Educação Financeira, volume 1: problemas financeiros e seus reflexos no ambiente de trabalho. Piracicaba: [s.n.], Elisson Augusto Pires de Andrade, 2012. Disponível em: http://profelisson.com.br/wpcontent/uploads/2012/03/Vol_1_-vers\%C3\%A3o_final.pdf. Acesso em: 16 maio 2018.

BARBOSA, F. Brasil vive pior ciclo econômico em mais de 20 anos, diz FMI. O Globo, 29 abr. 2015. Disponível em: https://oglobo.globo.com/economia/brasil-vive-pior-cicloeconomico-em-mais-de-20-anos-diz-fmi-16012985. Acesso em: 26 maio 2018.

BRASIL. Decreto n ${ }^{\circ}$ 7.397, de 22 de dezembro de 2010. Institui a Estratégia Nacional de Educação Financeira - ENEF, dispõe sobre a sua gestão e dá outras providências. Brasília, 
DF, 22 dez. 2010. Disponível em: http://www.planalto.gov.br/ccivil_03/_ato20072010/2010/decreto/d7397.htm. Acesso em: 22 maio 2018.

CNC. Pesquisa CNC: Percentual de famílias com dívidas diminui em abril de 2018. CNC. Disponível em: http://cnc.org.br/sites/default/files/arquivos/analise_peic_abril_2018.pdf. Acesso em: 09 maio 2018.

CODACE. Cronologia trimestral do ciclo de negócios brasileiros. Disponível em: http://portalibre.fgv.br/lumis/portal/file/fileDownload.jsp?fileId=8A7C82C54DB5CA9F014E F8794F847120. Acesso em: 20 out. 2017.

DANA, S. Como o desemprego e a crise geram um círculo vicioso? G1, 01 abr. 2016. Disponível em: http://g1.globo.com/economia/blog/samy-dana/post/como-o-desemprego-ecrise-geram-um-circulo-vicioso.html. Acesso em: 22 set. 2017.

DIEBOLD, F. X.; RUDEBUSCH, G. D. Measuring business cycles: a modern perspective. Review of Economics and Statistics, v.78, n. 67-77, jun 1996.

Disponível em: https://www.sas.upenn.edu/ fdiebold/papers/paper4/pabc.pdf. Acesso em: 23 maio 2018.

EID JUNIOR, W. Estresse financeiro e produtividade no trabalho. Centro de Estudos em Finanças da EAESP, fev. 2009. Disponível em: http://www.leticiacamargo.com.br/wpcontent/uploads/2014/02/Estresse-Financeiro-e-Produtividade-no-Trabalho.pdf. Acesso em: 15 maio 2018.

ENEF - ESTRATÉGIA NACIONAL DE EDUCAÇÃO FINANCEIRA. $2^{\circ}$ Mapeamento Nacional das Iniciativas de Educação Financeira. Disponível em:

http://www.vidaedinheiro.gov.br/2-mapeamento/. Acesso em: 22 ago. 2018.

FGV-RJ. FUNDAÇÃO GETÚLIO VARGAS. Comitê de Datação de Ciclos Econômicos. Rio de Janeiro, 27 maio 2009. Disponível em:

http://portalibre.fgv.br/lumis/portal/file/fileDownload.jsp?fileId=8A7C823326CD886101273 ED74C6F5F1D. Acesso em: 08 maio 2018.

FRAGA, E.; LIMA, F. É prematuro concluir que a recessão acabou, afirmam economistas. Folha de São Paulo, São Paulo, 22 maio 2018. Disponível em:

http://www1.folha.uol.com.br/mercado/2017/06/1892016-e-prematuro-concluir-que-recessaoacabou-afirmam-economistas.shtml. Acesso: 08 maio 2018.

GARMAN, T. Employer's return-on-investment model for workplace financial education and assistance programs. Disponível em: https://pfeef.org/wp-content/uploads/2016/09/ROIFeb-2007.pdf. Acesso em: 21 ago. 2018.

IBGE. PIB cai 3,5\% em 2015 e registra R\$ 6 trilhões. Agência IBGE, 9 nov. 2017.

Disponível em: https://agenciadenoticias.ibge.gov.br/2013-agencia-de-

noticias/releases/17902-pib-cai-3-5-em-2015-e-registra-r-6-trilhoes.html. Acesso em: 16 maio 2018. 
IBGE. PNAD contínua: rendimentos de todas as fontes 2017. Rio de Janeiro: IBGE, 2018. Disponível em: https://biblioteca.ibge.gov.br/visualizacao/livros/liv101559_informativo.pdf. Acesso em: 09 maio 2018.

LAGUNA, E. Inadimplência sobre 3,5\% e chega a 62 milhões de brasileiros, diz pesquisa. Exame, 9 maio 2018. Disponível em: https://exame.abril.com.br/economia/inadimplenciasobe-35-e-chega-a-62-milhoes-de-brasileiros-diz-pesquisa/. Acesso em: 10 maio 2018.

LAKATOS, E. M.; MARCONI, M. A. Fundamentos de Metodologia Científica. 4.ed. São Paulo: Atlas, 2001.

LOIOLA, L. de P. O estresse financeiro em dois grupos de profissionais brasileiros. 2014. 54 f. Dissertação (Mestrado em Administração). Escola de Administração de Empresas de São Paulo, Fundação Getúlio Vargas, São Paulo, 2014. Disponível em:

http://bibliotecadigital.fgv.br/dspace/handle/10438/11512. Acesso em: 15 maio 2018.

MARTINS, D. Funcionários sem dívida, empresa produtiva. Diário do Comércio, 12 dez. 2014. Disponível em: https://dcomercio.com.br/categoria/gestao/funcionarios-sem-dividasempresa-produtiva. Acesso em: 15 maio 2018.

MASSARO, A. Alguns dados interessantes sobre o stress financeiro. Exame, 24 fev. 2017. Disponível em: https://exame.abril.com.br/blog/voce-e-o-dinheiro/alguns-dados-interessantessobre-o-stress-financeiro. Acesso em: 15 maio 2018.

MORAIS, I. A. C. de. Ciclo e indicadores antecedentes na indústria do Rio Grande do Sul. Nova econ, Belo Horizonte, v. 23, n. 1, p. 133-154, abr. 2013. Disponível em: http://www.scielo.br/scielo.php?script=sci_arttext\&pid=S010363512013000100005\&lng=en\&nrm=iso. Acesso em: 8 maio 2018.

OECD. OECD's financial education Project. Financial Market Trends, n. 87, october 2004. Disponível em: https://www.oecd.org/finance/financial-education/33865427.pdf. Acesso em: 16 maio 2018.

PRAWITZ et al. Employee financial distress, emotional health risk, and absenteeism.

Research Gate, jan. 2010, Disponível em:

https://www.researchgate.net/publication/228468448_Employee_financial_distress_emotional _health_risk_and_absenteeism. Acesso em: 15 maio 2018.

SAVOIA, José Roberto Ferreira; SAITO, André Taue; SANTANA, Flávia de Angelis. Paradigmas da educação financeira no Brasil. RAP, v. 41, n. 6, nov/dez 2007, p. 1121-1141. Disponível em: http://w.scielo.br/pdf/rap/v41n6/06.pdf. Acesso em: 21 ago. 2018.

SILVEIRA, D. Mercado tem 26,3 milhões de trabalhadores subutilizados, diz IBGE. G1, 17 ago. 2017. Disponível em: https://g1.globo.com/economia/noticia/taxa-de-desocupacao-caiem-11-estados-no-2-trimestre-diz-ibge.ghtml. Acesso em: 10 maio 2018.

SOUZA, F. T. G. Os efeitos do estresse financeiro no ambiente de trabalho brasileiro. 2017. Dissertação (Mestrado em Administração). Escola de Administração de Empresas de São Paulo, Fundação Getúlio Vargas, São Paulo, 2017. Disponível em: http://bibliotecadigital.fgv.br/dspace/handle/10438/18466. Acesso em: 22 maio 2018. 
SOUZA, P. Estresse por dívidas derruba a produtividade. Diário do Grande ABC, 16 de nov. 2013. Disponível em: http://www.dgabc.com.br/Noticia/494669/estresse-por-dividasderruba-a-produtividade. Acesso em: 21 maio 2018. 